\title{
ALBEDO OF YOUNG AND FIRST-YEAR ANTARCTIC SEA ICE
}

\section{(Abstract)}

by

Richard Brandt,

(Geophysics Program, University of Washington, Seattle, WA 98195, U.S.A.)

Ian Allison

(Glaciology Section, Antarctic Division, Earth Sciences School, University of Melbourne, Parkville, Vic 3052, Australia)

and

Stephen Warren

(Geophysics Program, University of Washington, Seattle, WA 98195, U.S.A. and

Glaciology Section, Antarctic Division, Earth Sciences School, University of Melbourne, Parkville, Victoria 3052, Australia)

Reflection of solar radiation was studied in the seasonal sea-ice zone off East Antarctica on a cruise of the Australian Antarctic Expedition, October-December 1988. Spectral and total albedos were measured for grease ice, nilas, young grey ice, grey-white ice, snow-covered ice, and open water. Spectral measurements covered the region 400$1000 \mathrm{~nm}$ wavelength. For ice too thin to support our weight, the radiometers were mounted at the end of a $1.5 \mathrm{~m}$ rod extended out the door of a helicopter or from a basket hung from the ship's crane, using a positioning and leveling rack. Corrections had to be applied to the downward radiation flux because the helicopter or the crane was in the field of view of the cosine-collector.

The fractional coverage of each of the ice types (and open water) was estimated hourly for the region near the ship, as well as the thickness of each ice type, and the snow thickness. Observations were carried out continuously during the four weeks the ship was in the ice, supplemented by occasional helicopter surveys covering larger areas. These observations, together with the radiation measurements, make possible the computation of areaaverage albedo for the East Antarctic sea-ice zone in spring.

\section{NON-SYNCHRONOUS RESPONSE OF RABOTS GLACIAR AND STORGLACIAREN TO RECENT CLIMATIC CHANGE}

\section{(Abstract)}

by

Keith A. Brugger*

(Department of Geology and Geophysics, University of Minnesota, Minneapolis, MN 55355, U.S.A.)

Rabots glaciär and Storglaciären are small valley glaciers located in the Kebnekaise massif of northern Sweden. Rabots glaciär flows west from the summit of Kebnekaise $(2114 \mathrm{~m})$ and Storglaciären flows east; thus regional climate affecting the glaciers is the same. The glaciers are of comparable size and geometry, although differences exist in the variation of ice thickness and the subglacial bedrock topography within the respective basins. The thickness of Rabots glaciär appears to be relatively uniform over much of its length and its bed smooth. The bed over which Storglaciären flows is characterized by a "riegel and basin" topography and ice thicknesses vary accordingly.

* Present address: Department of Geology, Colby College, Waterville, ME 04901, U.S.A.
Advance and retreat of the glaciers during the last 100 years has been documented by historical records and photographs, measurements of ice retreats, and detailed glacial and geological studies. Both advanced to their maximum 20th century extents around 1916. In their subsequent retreat, Rabots glaciär has lagged behind Storglaciären by 10 years.

Mass-balance studies for the years 1981-87 suggest that while the "local" climate for each glacier is slightly different (in terms of the magnitude of acumulation and ablation), variations in local climate are synchronous. Non-synchronous response of the glaciers is therefore attributed to differences in glacier dynamics, which are quite apparent when velocity profiles are compared. Ice velocities on Rabots glaciär vary little from an average of $-7.5 \mathrm{~m} / \mathrm{yr}$, resulting in a longitudinal strain rate, $r$, of about $6 \times 10^{-3} \mathrm{yr}^{-1}$. In 